\title{
Polyurethane: Recent Engineering Contributions
}

\author{
Dorel Feldman* \\ Faculty of Engineering and Computer Science, Concordia University, Canada
}

Submission: December 07, 2019; Published: January 08, 2020

*Corresponding author: Dorel Feldman, Faculty of Engineering and Computer Science, Concordia University, Canada

\begin{abstract}
Polyurethane is one of the most versatile polymers which stands out with a wide range of tunable properties such as chemical stability, flexibility, abrasion and scratch resistance, toughness and biodegradability. It is a unique polymer containing alternating soft and hard segments. This review covers the most recent (2018-2019) engineering research contributions done for the synthesis, properties and applications of the polyurethane foams, coatings, adhesives, sealants, elastomers, composites and insists on the important aspects and realizations related to the polyurethane flammability and acoustic.

Keywords: Polyurethane Synthesis; Applications; Properties; Flammability; Acoustics

Abbreviations: AC: Alternative Current; BPAF: 4,4' [2,2,2,-trifluoro-1-(trifluoromethyl)ethylidene] bisphenol; CNT: Carbon Nano tube; DAP: Dimer fatty acid band polyol; DC: Direct current; DMA: Dynamic mechanic analysis; DSC: Dynamic scanning calorimetry; DTP: N,N'N"'tri(dietoxy) phosphoramide; EG: Expanded graphite; EMD: Non-Reactive Phosphonate; EPUUS: Ureaurethane elastomer; FGO: Functionalized graphene oxide; FHPO-PO: Phosphorous Containing Polyether Polyol; FR: Fire Retardant; FTIR: Fourier Transform Infrared Spectroscopy; FTPU: Fluorinated Thermoplastic Polyurethane; G: Graphene; GO: Graphene oxide; HFBA 2,2,3,3,4,: heptafluoro-butiric acid 2,2-bis-hydroxymethylbutyl ester; HRR: Heat release rate; HPU: Hyper Branched Polyurethane; LMPET: Low Melting Polyester; LOI: Limited Oxygen Index; MW: Molecular Weight; PEG: Poly(ethylene glycol); PHRR: Peak Heat Release Rate; PPG: Poly (propylene glycol); POSS Polyhedral Oligomeric Silsequioxanes; PU: Polyurethane; PU FR: Polyurethane with FR; RO: Rape seed oil; SEM: Scanning Electron Microscopy; SPB: Soybean Oil Based Polyol; TEM: Transmission Electron microscopy; TGA: Thermo gravimetry analysis; THRR: Total heat release rate; THR: Total heat release; TPIA: Acylhydrazine; TPID: Disulfide bonds; TPU: Thermoplastic polyurethane; VOCs: Volatile organic compounds
\end{abstract}

\section{Introduction}

Polyurethanes (PUs) constitute one of the most versatile class of macromolecular compounds known nowadays. They can contain a diversity of functional groups such as ether, ester, amide, urea, biuret, alophanate, uretidione, carbodiimide, isocyanurate, along with the urethane one (-NH-CO-O-) which open possibilities to react with many other components. PUs are synthesized by polycondensation reaction in which the macromolecular chain increases as the reaction progresses. This reaction can produce linear, slightly branched, or hyper branched macromolecules like in thermoplastics or they may have a crosslinked network leading to thermosetings. A recent kinetics study highlights the difficulties in quantifying the synthesis of linear PUs [1]. The main chemicals used for PU synthesis are polyols, isocyanates, and chain extenders having hydroxyl or amine group. PU contains in its macromolecules soft and hard segments; the former are made by the reaction between isocyanate and polyol, and the latter by the reaction between isocyanate and chain extender, both these components having 2 or 3 functional groups. In the
PU macromolecule the polyol provides the elasticity, and the isocyanate provides the mechanical strength. Recently it has been reported new types of PUs made by the polyaddtion participation of diisocyanates. To perform the polyaddition with diols in order to obtain PU, mostly methylene diphenyl diisocyanate and hexamethylene diisocyanate were chosen [2]. A method for solving a system of bulk polyaddition of 2,4-toluene diisocyanate with 1,4-butanediol process balance equations, allowing the determination of the kinetic parameters is presented. The approach provides an opportunity to associate kinetic parameters with the average molar mass of the mixture and thus with the viscosity [3].

Beside PU as a simple polymer, it is also used in various types of composites together with other compounds. These can be molecular composites, fiber composites, and nano filled composites. Like in the case of other groups of composites the interaction matrix-filler plays an important role, for instance for PU nano composites the interface PU-nanofiller in cases of special 
silica, polyhedral oligomeric silsequioxanes (POSS), carbon nano tube (CNT), graphene $(\mathrm{G})$, graphene oxide (GO), metallic nano particles are also very important [4]. PUs are processed to obtain various products such as flexible and rigid foams for construction and furniture items, sport equipments, coatings, adhesives, sealants, elastomers, fibers, medicine products. Adding other components beside polyols and isocyanates during the PU synthesis contributes to the improvement of some PU properties. For instance, tridecanoic acid added to toluene diisocyanate based PU is able to extend its working time with minimal changes to physical and chemical properties [5]. Another example is that of recycled polyol and benzimidazole grafted onto PU to enhance the surface hydrophilicity [6]. Due to the effects of PUs on human health, the replacement of toxic isocyanates with biocomponents is one of the main recent research direction related to PU synthesis [7]. The raw components necessary for the synthesis of PU can be obtained from natural products to substitute petroleum as their basic resource. Compared to isocyanates, the biobased raw materials possess many advantages like biodegradability, sustainability, nontoxicity and environmentally benign attributes [8]. Polyester polyols from renewable resources have gained important interest in the PU domain. Without petroleum-based polyols, castor oil polyols have been used as soft segments in PU [9]. Biobased PUs was also obtained from fatty acids with double functionality synthesized through cross-metathesis of oleic acid and oleic alcohol [10]. With azelate polyols produced from n-alkanediols with even number of $\mathrm{CH}_{2}$ repeating units thermoplastic PUs (TPU)s result with increased hardness, tensile and tear strength [11].

From crystalline azelate polyol and amorphous azelate polyol two sets of segmented TPUs were prepared. Their study showed that the crystalline azelate polyols are suitable for dynamic applications and the amorphous ones are suggested for coatings and adhesives [12]. The product of 1-butene methatesis of canola triacylglicerol with shortened structure, terminal double bonds and oligomers was used to synthesize novel polyols and PU foams. The study highlights that one can improve and control jointly the mechanical properties and deformation recovery ability of biobased PU foams by combining primary functional group oligomers, and high molar volume molecules in the polyols [13]. Dimer fatty acid-based polyol (DAP) was used to substitute petrochemical DAP and has been used to produce rigid PU foam. The research data indicated that bio-polyol DAP can substitute partial petrochemical polyol to produce rigid PU foams with good comprehensive performance [14]. A series of PUs nonisocyanate were produced from the transurethanization between 2,5-bis(hydroxymethyl)furan and dicarbamates obtained from metoxycarbonylation of diamines with dimethyl carbonate [15]. Other example of studies using bio-components will be presented. This paper will review the most recent studies done on PU products like foams coatings, adhesives, sealants, elastomers, and composites, and on flammability and acoustic properties.

\section{Research Contributions}

\section{Foams}

During the production of PU foam using aminophosphonated polyols the thermal resistance was confirmed and a lower peak of heat release rate (PHRR) and lower smoke production was found [16]. A polyol obtained by glycolysis of waste rigid PU foams was used to produce a new rigid foam. This new foam showed higher compressive strength, thermal insulation, and self-extinguishing property compared with conventional foam [17]. Liquefied rice husk with different $\mathrm{NCO} / \mathrm{OH}$ ratios was used to produce PU foams [18]. The effect of crosslinking agent on the properties and morphology of semi-rigid waterborn PU (WPU) foam was studied. The crosslinking density of the foams was adjusted by varying the amount of triethanolamine. The most characteristics processes to produce the foam are related to foaming and gelation. Increasing the amount of triethanolamine the crosslinking density increased and the swelling ratio decreased from 294.9 to $194.7 \%$, Tg increased from -14.2 to- $8.6{ }^{\circ} \mathrm{C}$ [19]. To optimize the formulation of a PU foam for better sound absorption, a study was carried out with a response surface methodology to investigate the effects of different variables, catalysts and polyethylene fiber. For correlating experimental data, a mathematical model was developed, and model parameters were optimized by adoptive simulated annealing algoritm [20]. The optimization of rigid WPU foams obtained from a polyol functionalized with GO has been the object of a recent study. A series of rigid WPU foams were synthesized by varying either the isocyanate index, catalyst amounts, the surfactant contents or a combination of these three components. The obtained results show how controlling WPU formulations allows to improve important properties like mechanical and thermal of rigid WPU foams containing GO [21]

The effects of shear thickening fluid content and $\mathrm{SiO}_{2}$ size on the cell structure, mechanical performance, acoustic absorption, and thermal performance of shear thickening fluid/PU foam were explored [22]. Adding to a flexible PU foam a negative powder modified with a silane coupling agent led to the improvement of important properties such as thermal stability, tensile strength and resilience [23]. Diferential scanning calorimetry (DSC), thermo gravimetry analysis (TGA), and Fourier transform infrared spectroscopy (FTIR) were used to measure the thermokinetics and degradation of soybean oil-based PU foam. The thermodynamic properties and thermal stability during the degradation were also studied. The degradation included 3 or 4 step-degradation profiles. As the soybean oil content or $\mathrm{NCO} / \mathrm{OH}$ molar ratio increases, the thermal stability of the foam, the activation energy, and reaction rate increased [24]. A technique for the production of new cheaper components able to substitute polyols for the production of PU-polyisocyanurate foams is presented. The influence of the components on the foam flammability, thermal properties and other characteristics was examined [25]. 


\section{Coatings}

New biobased PU coatings with lignin were studied. A diisocyanate obtained from lignin-derived vanilic acid and crosslinked with three different nonchemically modified technical lignins namely mild acetone organosolv, kraft, and soda. The results of the research showed that the reaction of a ligninderived biobased diisocyanate represent an interesting way for the production of TPU coating. The study also showed that the reaction of lignin-derived biobased diisocyanate represents an interesting way for the production of TPU coatings with a high biomass content that can find applications as an alternative to petroleum products [26]. By using stoichiometric proportions of PU polyamines and aliphatic epoxies as crosslinker, coatings were produced. These new products possess flexibility at low temperatures and resistance to chemicals, but their thermostability is low [27].

Fully biobased polyester polyols were prepared and used for PU coatings by reacting with diisocyanate. The mechanical, chemical and thermal properties demonstrated that the renewable sources used for the production of PU coatings can be good substitutes for petroleum products [28]. The structural and morphological characteristics of functionalized graphene oxide (FGO)/PU coatings were characterized by transmission electron microscopy (TEM) and scanning electron microscopy (SEM). Beside a chemical reaction between the two components they are able to effectively enhance the thermal, flame retardant and mechanical properties of the coatings [29]. Siloxane-semifluorinated PU coatings were synthesized for robust underwater applications [30].

The state-of-the-art of isocyanates and polyisocyanates of the various PU crosslinking mechanisms and the corresponding applications are presented. Aspects ranging from the replacement of oil-based PU components by biobased equivalents to the development of new synthetic pathways for the production of polyhydroxy polyurethanes for coatings have been also investigated [31]. A study of a PU network of polyaniline, poly$\mathrm{m}$-amino phenol and poly- $\alpha$-anisidine coated on a mild steel panel was reported. The coated films showed excellent corrosion protection in the following order: PU-polyanilin>PU-poly-maminophenol>PU-poly- $\alpha$-anisidine [32].

As an alternative to PU coatings based on toxic components, the synthesis of poly (hydroxy urethanes) by cyclocarbonate aminolysis constitutes a solution to avoid emissions of volatile organic compounds (VOC)s. Thus, developing their technology became important [33]. Using polyblends of WPU and polyacrylate porous-coated fabrics for synthetic leather were produced. The $\mathrm{H}$ bonds between the polymers were proved by FTIR and DSC. The best performance of coated fabrics was found at the ratios from $15 / 85$ to $30 / 70$ polyacrylate /PU [34]. Novel PU coatings were produced by polycondensation of hydroxylationterminated poly (L-lactide) (PLLA) functionalized graphene
(G-g-PLLA) and isocyanate terminated PU oligomer with dimethylsiloxane. The functionalized PU was able to hydrolyze in seawater and the hydrolysis rate decreased with the increase of polydimethylsiloxane amount. The new coatings exhibited good antifouling [35].

Polymers containig spirooxazine were grafted and doped with WPU used as an environmentally friendly coating. The obtained films had improved water resistance, mechanical and photochromic properties [36]. TPU was blended in tetrahydrofuran with polyphosphate containing furfuryl and trifluorothoxy groups. Using FTIR, DSC, scanning electron microscopy (SEM) and limited oxygen index (LOI) the obtaining films were analyzed. The results demonstrated that the addition of $20 \%$ phosphazene in the blend enhanced the tensile strength by about $110 \%$ and decreased the elongation at break by nearly $13 \%$ [37].

PU synthesis and film forming using the asymmetric cyclic aliphatic diisocyanate -isophorone diisocyanate with acetylated and pristine partially hydrolyzed amylopectine/white dextrin as a crosslinker has been studied [38]. From isophorone diisocyanate, poly (ethylene glycol), aminopropyl terminated poly (dimethyl siloxane) and 1,4-butandiol via two-step polycondensation, new PU membranes were produced [39]. To obtain a $\mathrm{pH}$ responsive hybrid films different amounts of 2-(diethylamino) ethyl methacrylate and PU based on isophorone diisocyanate were used for heavy metal ions removal. The study revealed that functional groups of 2-(diethylamino) ethyl methacrylate are the main sorption sites for the metal ions [40].

\section{Adhesives}

A PU powder used as adhesive was synthesized by solution polymerization. The influence of molar ratio of $-\mathrm{NCO}$ to $-\mathrm{OH}$, neutralization and types of solution dispersion on the properties of the adhesive were studied. Excellent adhesive properties were found, and that the adhesive thermostability could meet the requirements of industrial gluing for packaging, lining and footwear [41]. A research concluded that WPU could enhance its adhesive characteristics with materials of different natures and structures [42]. A review compares the properties and the use of petrol-based PU with biobased PU for adhesive technology. To reduce the VOCs, PU based on castor oil was preferred as bio raw material [43]. A study insists on the role of accurate selection of diisocyanate -which induces the hard segments- on the viscoelastic and the adhesion properties of PUs. The polyblend studied consists of a mixture of a macrodiol of hydroxyl terminated polybutadiene, polypropylene glycol (PPG) and isophorone diisocyanate necessary to develop the urethane linkages. The controlled quantities of hard and soft segments resulted in better adhesive properties and the balance is realized by the selection of the isophorone diisocyanate [44].

By incorporating synthetic glycerol mono -methacrylate, underwater PU adhesives were produced. The study confirmed 
that this incorporation induced increasing cohesion and adhesive strength superior to that of pure PU [45]. A new PU sealant for insulating glass based on a nucleophilic substitution reaction between the p-chlorophenol-terminated PU prepolymer and a poly-functional hyper branched polyamine has been synthesized. After crosslinking-curing it was found that the sealant is applicable in a wide temperature range, is not sensitive to moisture, is easy to store, and does not corrode the substrate; all of these as well as its mildew resistance and low cost [46].

\section{PU Elastomers}

Poly (ethylene glycol) (PEG) grafted GO was blended with $\mathrm{PU}$ elastomer. Their interaction was produced by $\mathrm{H}$ bonding. Due to it the strength and toughness of vulcanizate rubber were significantly improved and the blend Tg shifted to higher temperature [47]. Two PU elastomers, one having acylhydrazine (TPIA) and the other disulfide bonds (TPID) were synthesized, and their self-repairable ability and reprocess ability have been investigated. The conclusion of the study was that TPIA elastomer can be repaired under acidic conditions, and the TPID can autorepair under visible light at room temperature [48]. In the case of a polyblend of epoxidized natural rubber/TPU it was found that rice husk ash particles had stronger interactions with epoxidized natural rubber and provided enhanced mechanical properties to the rubber [49]. TPU elastomers having aliphatic polycarbonate soft segments and hard segments made by 1,1'-methanediylbis(4isocyanato-cyclohexane) or 1,6-diisocyanatohexane and a combination of two chain extenders were synthesized in one-step catalyzed polyaddition [50].

To evaluate the effect of rape seed-oil-based (RO) polyol on the properties of tested urea urethane elastomers (EPUUS) was the objective of a new study. FTIR, thermo gravimetry analysis (TGA), DSC, DMA, static tensile strength and physico-mechanical tests were applied. The use of RO polyol in polyol premixes changed the chemical structure of EPUUS showing a modification in the amount of H-bonds and the degree of phase separation. An increase in Tg of the soft phase was also established [51].

\section{Composites}

Thin laminated composite has been produced by blending TPU with low-melting polyester (LMPET) and Kevlar fibers. The presence of Kevlar enhances the tensile properties and flame resistance. The tensile strength of the composite reaches 18.85 $\mathrm{MPa}$ and the combustion rate is reduced [52]. The effects of temperature, humidity and automotive fluids on the long-term durability of the two types of glass fiber reinforced PU has been investigated. Variation of mass, flexural strength and viscoelastic response are determined in order to find the changes of the composite [53]. A comparison of TPU/GO and TPU/reduce GO showed that the reduction of GO is not always necessary [54]. The dynamo- mechanical, thermal and mechanical characteristics of long glass fiber reinforced TPU / poly (butylene terephthalate) polyblend have been studied. A good compatibility was found between the two polymers. DMA showed that the TPU content had some influence on dynamic- mechanical properties and the $\mathrm{Tg}$ of the long glass fiber reinforced polyblend. DSC indicated that with the increase of TPU amount the crystallization temperature, the melting point and the percent of crystallinity decreased. The TPU presence contributes to a remarkable increase of some mechanical characteristics but also produces a decrease of flexural and modulus of elasticity [55].

Using melt-blending a hybrid made of a shape memory TPU with GO and montmorillonite (MMT) was produced. Thermal analysis showed that GO-MMT enhanced the thermal decomposition of TPU composites [56]. Expandable graphite (EG) is often added to PUs to prevent their flammability. Such graphite was incapsulated in melamine cyanurate and after that was added to rigid PU. It was established that the mechanical properties of the polymer were improved. This composite decomposes faster and produces more smoke than the PU without EG. The obtained data show that melamine cyanurate and EG have a synergistic enhancing effect on the flame retardancy of the composite [57]. A composite made of PU reinforced with sugar palm fiber and glass fiber is recommended to be used in applications that require resistance to high temperature [58]. Carbon fiber-GO reinforcement improved thermo-mechanical and thermal stability of PU due to the carbon fiber- PU improved interfacial interaction as well as the local stiffening of fiber-matrix interphase by the dispersed GO sheets [59].

A PU and red mud composite, the mud in micron particles uniformly embedded in PU, exhibited satisfactory mechanical performance and the compressive and flexural strength are, after complete curing, up to 38.6 and 12.4 MPa. It also displayed very good thermal stability, flame retardancy, storage stability, and reinforcement [60]. The heat conducting with focus on the enhancement of thermal conductivity of WPU composites through compatibility and feasibility of hybrid techniques is reviewed [61]. In a research PU foam was filled with paper waste sludge (5\% by foam mass). It was found that the thermal conductivity, water vapor resistance, density, compressive strength, and modulus of elasticity were improved [62].

By using the ring-opening reaction of cyclic carbonate with excess amine and methanol to increase the molar mass of $-\mathrm{NH}_{2}$ terminated non-isocyanate PU prepolymer, its performance was improved. By adding bisphenol A diglycidyl ether into the prepolymer a hybrid was obtained which has good mechanical properties, a $\mathrm{Tg}-49,1{ }^{\circ} \mathrm{C}$ and a good thermal stability [63]. Applying a low melting point chain extender, the raw components being 1,4-butanediol and dimethyl propionic acid a study showed that with the decrease of the ratio of dimethyl propionic acid/1,4butanediol the mechanical properties of the PU decreased [64]. 
To control the soft segment thermal properties and to enhance tensile strength, shape memory and low temperature flexibility, norbornen was grafted onto PU. This grafted PU demonstrated enhanced low temperature flexibility due to reduce restrictions of rotational and translation mobility [65].

A new molecular design was proposed by incorporating 2-ureido-4-[1H]-pyrimidone motifs in the backbone chains of PU to enhance the mechanical performance and using a triol functional Diels-Alder crosslinker to realize PU healable and recyclable [66]. New PUs made with homocubane $\left(\mathrm{C}^{\prime} \mathrm{i}_{0} \mathrm{Hi}_{0} \mathrm{O}_{2}\right)$ based diols and diisocyanates were synthesized. They are soluble in polar organic solvents, decompose at relatively high temperature, and the Tg is higher than those of commercial PUs. It is expected that these new polymers will find application in products that need thermally robust PUs [67]. One pot technique for the production of GO/(hyper branched PU)(HPU) has been presented. The composite obtained shows very good increase in the mechanical properties due to the covalent bonding realized between GO and isocyanate component and an excellent load transfer. Mild increase in stability towards thermal degradation and higher dielectric constant compare with HPU at low frequency was also found [68].

The effects of polyhydric alcohols on the mechanical and thermal properties, porosity and air permeability of PU composites have been studied. With increasing polyhydric alcohol amount, the tesile strength and $\mathrm{Tg}$ decrease remarkably. The swelling capacity and porosities of the PU/propylene glycol (PPG)-blended and PU/glycerol blended films increased with the increase of PPG or glycerol amount [69]. In composites TPU/wood flour the properties depend on the ratio between the components; it was established that the presence of the wood flower contributes to the increase of important properties such as density, hardness, water absorption, tensile modulus; impact and and abrasion resistance decrease [70]. The high electrical resistivity of blast furnace slag and fly ash make these materials an asset for use in rigid PU foams for insulation [71]. A PU/melamine formaldehide composite foam was prepared through foaming PU. The foam composite showed satisfactory fire retardancy and good comprehensive properties [72].

PU composites which could be used as damping materials with different amounts of hydroxyl silicone oil were prepared. The damping, mechanical properties, thermal stability and molecular groups were established. It was found that the composites with 8\% hydroxyl silicone oil possess the best properties [73]. Sandwich composites made of a core of flexible PU foam and nonwoven poly (ethylene terephthalate) as the top and bottom panels were produced. The research found that such composites have functionalities of FR efficacy, acoustic absorption, heat insulation, electromagnetic shielding effectiveness and thus are suited for protective partitions [74].

\section{Flammability}

PU foams are in general flammable and their flammability is controlled by using flame-retardants (FR)s. Phenyl phosphonic acid and propylene oxide-based reactive FR polyol, together with limonene based polyol have been used for the preparation of FR/ PU foams. The phosphorous based polyols could be mixed with bio-based polyols to prepare highly fire retardancy and superior physico-mechanical rigid PU foams [75]. The study of a rigid PU foam showed that 3,3',4,4'-biphenyltetracarboxylic dianhydride and 9,10-dihydro-9-oxa-(10-glycidoxypropilene)-10-phosphaphenantrene-10-oxide lead to an increase in graphite in the fire residue and the formation of a better barrier to prevent burning by the condensed phase mechanism [76]. Rigid PU modified with microencapsulated red phosphorous, $\operatorname{Mg}(\mathrm{OH})_{2}$, glass filler and hollow glass bead were prepared and showed that the fire retardancy and the combustion were improved [77].

A new, inherent, fire retardancy of the foams based on imide and oxazolidinone were investigated by LOI , vertical burning test and calorimetry. Cone calorimeter test data showed also that EG reduced the heat release rate (HRR), total heat release ( THR), and total smoke production. A low amount of EG added to PU increased the compression strength but as the amount increases the compression strength decreases [78]. It was found that the EG modified by poly (methyl methacrylate) and poly (glycidyl methacrylate) is an important product as a FR for foams made of PU-polyisocyanurate [79]. FR/ PU foams containing a nonreactive phosphonate (EMD) and EG were produced. This new complex increased the LOI and decreased the total heat release rate ( THRR), average effective combustion heat, peak heat release rate (PHRR) and total smoke release of the PU foams [80].

New polyols containing 0.8-1.2 wt\% boron and 7.9-8.5 wt\% nitrogen were used to obtain rigid PU foams. LOI test as horizontal and vertical flammability tests showed reduced flammability and also improved thermal, dimensional stability and mechanical properties [81]. PU foams were also produced by mixing with a phosphorous containing polyether polyol (THPO-PO) and soybean oil-based polyol (SBP).Although the thermal stability of the foams decreased with the increase of THPO-PO amount, the flame retardancy was improved. LOI increased 40\% .THPO-PO worked in inhibiting flame and forming phosphorous rich char layer [82]. A polyol made of mercaptenized castor oil and diethyl allyl phosphonate was used for preparing PU foams having different amounts of phosphorous. The closed cells amount in all the foams was above $95 \%$.The results of flammability tests suggest that in the synthesis polyol could act as an essential FR for rigid PU foams ensuring fire safety [83].

The fire characteristics (heat and smoke) were studied using calorimetry test in the case of a composite made of rigid PU foams and flax fibers treated with a FR. The obtained research data showed that treated flax fibers besides improving the mechanical 
properties of the foam had a good prospect in reducing the fire hazard [84].

A new FR based on a P-N compound namely $\mathrm{N}, \mathrm{N}$ "N"'tri(diethoxy) phosphoramide (DTP) was synthesized and added to WPU foams. According to TGA data the combination restrained the decomposition, enhanced the residue at high temperature, higher LOI data were obtained and lowered the HRR. The cone calorimetry test indicated that the EG/DTP system jointly inhibited the fire intensity and the smoke production [85].

After a surface modification EG was introduce also in foams based on PU-imide. The foams exhibited outstanding enhancements compare to that of only pristine EG introduction in compressive strength, thermal stability and flame resistance [86]. Four wood-based wastes were incorporated into rigid bio-based PU foams; these were characterized by thermal and combustion properties. Filled PU foams with such wastes showed higher thermal and dimensional stability, however the thermal conductivities and flammabilities were similar to neat foam [87].

\section{Acoustics}

Using polycaprolactone diol, toluene diisocyanate, hydroxyl fluorosilicate and 2,4-diamino-3,5-dimethyl thiotoluene, a new Fluor silicon polyester PU was synthesized. The study of its properties indicates that it has an excellent water resistance which has acoustic performance, a low Tg and the fact that it is an ideal transparent product for underwater acoustics [88]. Using linear saturated aliphatic polyesters, methylene diphenyl diisocyanate and other reagents, high performance acoustic damping flexible PUs were produced. The study showed that sound proofing flexible PU foams under optimum conditions can be promising candidates for use as sound-insulating products [89].

With the finite element method PU sound absorbing panels were designed using for material formulation Comsol able to provide optimum performance of echo reduction with minimum thickness. The research shows that by judicious choice of matrix/ filler combination it is possible to achieve selective/broadband absorber for underwater applications [90]. Using Tung oleic acid-base polyol and polyether polyols a new biobased PU foam different from common PU foam was prepared. The study found that the biobased PU mean sound absorption coefficient and transmission loss can reach 0.515 and $21.389 \mathrm{~dB}$ [91].

\section{Other Contributions}

Fluorinated TPU (FTPU) elastomers based on 3-isocyanatomethyl-3,5,5-trimethylcyclohexyl isocyanate poly(tetramethyl glycol) polycaprolactone and 4,4'[2,2,2-trifluoro-1-(trifluoromethyl) ethylidene] bisphenol (BPAF) have been synthesized. The study of their properties showed that the thermal stability and mechanical properties are significantly improved by BPAF [92].
Fluorinated PUs (FPU)s having various amounts of fluorinated chain extender and the same amounts of poly (oxytetramethylene glycol) and diphenyl methane diisocyanate were synthesized in view to find the relationship between surface physico-chemical properties, the bulk microphase separation structures of these FPUs and their antifouling. The conclusion of the study is that the increased microphase separation of FPUs results in enhanced antifouling properties [93]. A WPU prepolymer was obtained based on poly(tetramethyleneglycol), isophorone diisocyanate and 2,2,3,3,4,4-heptafluoro-butyric acid 2,2- bis-hydroxymethylbutyl ester (HFBA) for a series of HFBA/WPUs; ethylenediamine was used as the chain extender. In vitro platelet and erythrocyte adhesion experiments revealed that increasing HFBA content also enhanced the hydrophobicity and reduced blood adhesion to the HFBA/WPUs [94].

The effect of the type of diisocyanates and glycols, degree of crosslinking, the amount of hard segments, crystallinity, the amount of hydrophilic groups on optical properties of WPU have been studied focusing on the matting effect and transmittance. The particle size of PU latex was the most important factor to influence the matting [95]. The effects TPU with various amounts of boron nitride has on DC and AC conductivities and the free volume have been investigated [96]. Results of dielectric/electrical studies of onion-like carbon/PU composite films in very broad frequency and temperature are presented in a study [97]. By studying the spinning technique and the fiber topology, it was found that the characteristics of the PU solutions influence the spinning process and is able to affect the fiber topology [98].

\section{Remarks}

Taking into account its versatility, polyurethane is used in many engineering areas and in medicine.

Its interesting properties led to the intensification of academic and industrial polyurethane research in the fields of synthesis, properties, and applications. Many realizations presented in this review obtained so far at the laboratory level are applicable at the industrial one.

\section{References}

1. Polo ML, Sponton ME, Jaramillo F, Estenoz DA, Meira GR (2018) Linear segmented polyurethanes: I. A kinetics study. J Appl Polym Sci 135(4): 45747.

2. Akbulut H, Yoshida Y, Yamada S, Endo T (2019) Synthesis and physical properties of poly(urethane)s using vicinal diols derived from acrylate and styrene monomers. J Polym Sci Part A, Polym Chem 57(7): 799805 .

3. Mederski T (2019) Modelling polyurethane synthesis rates on the example of heteropolyaddition of 2,4-toluene diisocyanate (TDI) and 1,4-butanediol (BD). Polym Bull 76: 2427-2438.

4. Rao YQ (2017) Engineering of interface in nanocomposites based on polyurethane polymers. In: Thomas S, Datta J, Haponiuk JT, Reghunadhan A (Eds) Polyurethane polymers by Reghunadhan Elsevier p. 74-126. 
5. Reardon S, Caroll AL, Dumont JH, Park CH, Lee KS (2019) Extending the working life of toluene diisocyanate-based polyurethanes. J Appl Polym Sci 136(33): 47865.

6. Chung YC, Lee DH, Choi JW, Chum BC (2018) J Appl Polym Sci 135 46600 .

7. Yu AZ, Setien RA, Sahouani JM, Docken J, Webster DC (2019) J Coat Technol Res 16(1): 41-57.

8. Karak N (2017) Biobased smart polyurethane nanocomposites. From synthesis to applications. Royal Society of Chemistry: 1-9.

9. Zhang J, Yao M, Chen J, Jiang Z, Ma X (2019) Synthesis and properties of polyurethane elastomers based on renewable castor oil polyols. J Appl Polym Sci 136(14): 47309.

10. Aguilar Castro C, Gomez MD, Nava MG, Garcia JMR, Lugo Urile LE (2019) J Appl Polym Sci 136: 47095.

11. Tuan Ismail TNM, Ibrahim, NA, Sendijarevic A, Sendijarevic I, Schiffman CM, et al. (2018) Oscillatory structure-property correlation in azelate polyols and thermoplastic polyurethanes. J Appl Polym Sci 135(19): 46258.

12. Tuan Ismail TNM, Ibrahim NA, Sendijarevic V, Sandijarevic I, Schiffman CM, et al. (2019) Thermal and mechanical properties of thermoplastic urethanes made from crystalline and amorphous azelate polyols. J Appl Polym Sci 136(34): 47890.

13. Pillai PKS, Bouzidi L, Narine SS (2018) Polyurethane foams from chlorinated and non-chlorinated metathesis modified canola oil polyols. J Appl Polym Sci 135(33): 46616.

14. Yang R, Wang B, Xu L, Zheo C, Zhang X, Li J (2019) Polym Bull 76: 37533768.

15. Zhang L, Michel FC, Co AC (2019) J Apl Polym Sc Polym Chem 57: 1496-1499.

16. Boneguero AM, Velencoso MM, Rodriguez JQ, Serrano A, Canerro M (2019) J Appl Polym Sci 136: 47780.

17. Shin SR, Kim HN, Liang JY, Lee SH, Lee DS (2019) High-quality freestanding flexible poly(5-(2,3-dihydrothieno[3,4-b][1,4]dioxin-5yl)-1H-indole) film: Electrosyntheses, characterization, and optical properties. J Appl Polym Sci 136(2): 47016.

18. Lee WJ, Yu CY, Chen YC (2018) Preparation and characteristics of polyurethane made with polyhydric alcohol-liquefied rice husk. J Appl Polym Sci 135(8): 45910

19. Luo Y, Zou J, Li J, Zou H, Liang M (2018) Effect of crosslinking agent on properties and morphology of water-blown semirigid polyurethane foam. J Appl Polym Sci 135(42): 46753.

20. Zhu T, Chen S, Zhu W, Wang Y (2018) Optimization of sound absorption property for polyurethane foam using adaptive simulated annealing algorithm. J Appl Polym Sci 135(26): 46426.

21. Santiago CM, Blasco V, Ruiz C, Paris R, Villafazie F, et al. (2019) Improvement of thermal and mechanical properties by control of formulations in rigid polyurethane foams from polyols functionalized with graphene oxide. J Appl Polym Sci 136(19): 47474

22. Li TT, Ling L, Wang X, Jiang Q, Liu B, et al. (2019) Mechanical, acoustic, and thermal performances of shear thickening fluid-filled rigid polyurethane foam composites: Effects of content of shear thickening fluid and particle size of silica. J Appl Polym Sci 136(18): 47359.

23. Wang X, Wang M, Li Q (2019) J Macrom Sci Part A Pure, Appl Chem 56(11): 1035-1039.

24.Zhou X (2019) Thermokinetics study of degradation process of soybean-based polyurethane foams. J Appl Polym Sci 136(16): 47357.
25. Liszkowska J (2017) The use of citric acid in the production of polyols for rigid PUR-PIR foams. Polym Bull 74(1): 283-305.

26. De Haro JC, Allegreti C, Smit AT, Turri S, Arrigo P, et al. (2019) ACS Sustainable Chem Eng 7(13): 11700-11711.

27. Asemani H, Zareanshahraki F, Manari V (2019) J Appl Polym Sci 136: 47266.

28. Khanderay JC, Gite VV (2019) Fully biobased polyester polyols derived from renewable resources toward preparation of polyurethane and their application for coatings. J Appl Polym Sci 136(22): 47558.

29. Qian X, Jiang S (2018) Polym Compos 39: 746-754.

30. Sebstin AY, Mohany S, Nayak SK (2019) Synthesis and characterization of eco-friendly siloxane-semifluorinated polyurethane coatings for underwater application. J Appl Polym Sci 136(27): 47720.

31. Golling FF, Pires R, Hecking A, Weikand J, Richter F, et al. (2019) Polym Int 68: 848-855.

32. Karmakar HS, Amkula R, Theta A, Narayan R, Rao CRK (2018) Polyaniline-grafted polyurethane coatings for corrosion protection of mild steel surfaces. J Appl Polym Sci 135(6): 45806.

33. Llevot A, Meier M (2019) Polym Int 68: 826-831.

34. Zheng G, Lu M, Rui X, Sun Y (2018) The effect of acrylate on structure and properties of waterborne polyurethane porous coated fabrics. J Appl Polym Sci 135(5): 45783.

35. Ou B, Chen M, Guo Y, Kang V, Guo Y, et al. (2018) Polym Bull 75: 51435162.

36. Cai G, Shi M, Gao J, Yuan L (2019) Preparation and photochromic properties of waterborne polyurethane containing spirooxazine groups. J Appl Polym Sci 136(7): 47067.

37. Singh KP, Mishra A, Kumar N, Tripathti DN, Shani TC (2018) Polym Bull 75: 2415-2430.

38. Konieczny J, Loss K (2010) Bio-based polyurethane films using white dextrins. J Appl Polym Sci 136(20): 47454.

39. Zheng Y, Hu Y, Yang X, Yuan N, Zhang J, et al. (2019) J Appl Polym Sci 136: 47723.

40. Parchni FM, Faccia PA, Amalvy JI (2018) Heavy metal ions removal from water using a smart polyurethane/acrylic hybrid. J Appl Polym Sci 135: 46874

41. Sun M, Ren X, Zhang X, Wang H (2019) Structure variation and puncture resistance of stretched crosslinked polyethylene film: Effects of stretching temperature. J Appl Polym Sci 136: 47898.

42. Akram N, Zia KM, Saeed M, Usman M, Saleem S (2018) Impact of macrodiols on the adhesion strength of polyurethane pressuresensitive adhesives. J Appl Polym Sci 135: 46635.

43. Sahoo S, Mohanty S, Nayak SK (2018) Biobased polyurethane adhesive over petroleum-based adhesive: Use of renewable resource. J Macrom Sci Part A Pure Appl Chem 55(1): 36-48.

44. Akram N, Zia KM, Saeed M, Usman M, Khan WG (2019) Role of isophorone diisocyanate in the optimization of adhesion tendency of polyurethane pressure sensitive adhesives. J Appl Polym Sci 136: 47124.

45. Li X, Li W, Liu Z, Weng X, Guo H, et al. (2018) Underwater polyurethane adhesive with enhanced cohesion by postcrosslinking of glycerol monomethacrylate J Appl Polym Sci 135: 46579.

46. Li W, Liu X, Wu J, Wu L, Sun A, et al. (2019) Two-component modified polyurethane sealant for insulating glass: Design, preparation, and application. Appl Polym Sci 136: 48219. 
47. Wang L, Fu W, Peng W, Xiao H, Li S, et al. (2019) Enhancing Mechanical and Thermal Properties of Polyurethane Rubber Reinforced with Polyethylene Glycol-g-Graphene Oxide. Adv Polym Technol.

48. Wang X, Wei Y, Chen D, Bai Y (2017) Synthesis and properties of roomtemperature self-healing polyurethane elastomers. J Macrom Sci Part A Pure Appl Chem 54(12): 956-966.

49. Pondong W, Kummerlowe C, Vennemann N, Thitithammawang A, Nakason C (2019) Thermodynamically and kinetically favored locations of rice husk ash particles in the phase structure, and the properties of epoxidized natural rubber/thermoplastic polyurethane blends. J Appl Polym Sci 135: 46681.

50. Rogulska M (2019) Polycarbonate-based thermoplastic polyurethane elastomers modified by DMPA. Polym Bull 76: 4719-4733.

51. Mizera K, Ryszkoouska J, Kurouska M, Prociak A (2018) Production and characterization of ureaurethane elastomers with rapeseed-based polyol. Polym Int 67: 1605-1614.

52. Lin MC, Lou CW, Lin JY, Lin TA, Lin JH (2019) Structural improvement of laminated thermoplastic polyurethane/low-melting polyester/kevlar composites. Polym Compos 40: E550-E558.

53. Panaitescu I, Koch T, Archodoulaki VM (2019) Effects of temperature, humidity and automotive fluids exposure on glass fiber/polyurethane composites. Polym Compos 40: 2357-2367.

54. Wang Y, Chen X, Zhu W, Huang X, Tang XZ, et al. (2019) Thermal and mechanical properties of thermoplastic urethanes made from crystalline and amorphous azelate polyols. J Appl Polym Sci 136 47890.

55. Zhang D, He M, Qin S, Yu J, Guo J, et al. (2019) Study on dynamic mechanical, thermal, and mechanical properties of long glass fiber reinforced thermoplastic polyurethane/poly(butylene terephthalate) composites. Polym Compos 39: 63-72.

56. Zhou X, Hu B, Xiao WQ Yan L, Wang ZJ, et al. (2018) Thermal and mechanical properties of thermoplastic urethanes made from crystalline and amorphous azelate polyols. J Appl Polym Sci 135: 46149.

57. Cheng JJ, Qu WJ, Sun SH (2019) Mechanical properties improvement and fire hazard reduction of expandable graphite microencapsulated in rigid polyurethane foams. Polym Compos 40: E1006-E1014.

58. Atiqah H, Jawaid M, Sapuan SM, Ishak MR (2019) Dynamic mechanical properties of sugar palm/glass fiber reinforced thermoplastic polyurethane hybrid composites. Polym Compos 40: 1329-1334

59. Jiang S, He Z, Li Q, Wang J, Wu G, et al. (2019) Effect of carbon fibergraphene oxide multiscale reinforcements on the thermo-mechanical properties of polyurethane elastomer. Polym Compos 40 :E953-E961.

60. Yang Z, Shuai B, Zhang X, Yu H, Zhang H, et al. (2019) Fabrication and performance of a polyurethane hybrid composite with waste red mud. Polym Compos 40: 2424-2431.

61. Li R, Shan Z (2018) Polym Bull 75: 4823-4836.

62. Kairyte A, Kirpluks M, Ivdre A, Cabulis U, Vejelis S, et al. (2019) Polym Compos 39: 1852-1860.

63. Ke J, Li X, Jiang S, Liang C, Wang J, et al. (2019) Promising approaches to improve the performances of hybrid non-isocyanate polyurethane. Polym Int 68(4): 651-660.

64. Sun H, Chen D (2018) Polym Bull 75: 4913-4928.

65. Chung YC, Kim YJ, Choi TW, Chun BC (2018) Polym Bull 75: 2459-2474. 66. Li M, Zhang R, Li X, Wu Q, Chen T, et al. (2018) Polymer 148: 127-137.
67. Hwang C, Sultane PP, Kang DH, Bielawski CW (2018) Polym Int 67: 1664-1669.

68. Yadav SK, Suri A, Ansari MO, Thomas S (2018) Polym Compos 39: 2756-2770.

69. Lee JH, Min MH, Lee SG (2019) Effect of polyhydric alcohols on the mechanical and thermal properties, porosities, and air permeabilities of polyurethane-blended films. J Appl Polym Sci 136(11): 47429.

70. Diestel S, Krause A (2018) Wood-based composites with thermoplastic polyurethane as matrix polymer. J Appl Polym Sci 135(25): 46344.

71. Akkoyun M, Akkoyun S (2019) Blast furnace slag or fly ash filled rigid polyurethane composite foams: A comprehensive investigation. J Appl Polym Sci 136 (20): 47433.

72. Liao H, Li H, Liu Y, Wang Q (2019) Polym Int 68: 410-417.

73. Li L, Tian B, Li L, Shi M, Guan Y, et al. (2019) J Appl Polym Sci 136: 47579.

74. Wu LW, Ban JY, Jiang Q Li TT, Shiu BC, et al. (2018) Flexible polyurethane foam-based sandwich composites: Preparation and evaluation of thermal, acoustic, and electromagnetic properties. J Appl Polym Sci 135(48): 46871.

75. Bhoyate S, Ionescu M, Kahol PH, Chen J, Mishra SR, Gupta RK (2018) Highly flame-retardant polyurethane foam based on reactive phosphorus polyol and limonene-based polyol. J Appl Polym Sci135(21): 46224.

76. Jia D, Hu J, He J, Yang R (2019) Properties of a novel inherently flameretardant rigid polyurethane foam composite bearing imide and oxazolidinone. J Appl Polym Sci 136(37): 47943.

77. Li A, Yang DD, Li HN, Jiang CL, Liang JZ (2018) Flame-retardant and mechanical properties of rigid polyurethane foam/MRP/mg(OH) $)_{2} / \mathrm{GF} /$ HGB composites. J Appl Polym Sci 135(31): 46551.

78. Acuria P, Santiago Calvo M, Villafane F, Rodriguez Perez MA, Rosas J, et al. (2019) Polym Compos 40: E1705-1715.

79. Gosz K, Haponiuk J, Miclewezyk Gryn A, Piszyk L (2019) Polym Compos 40: 3805-3813.

80. Li L, Chen Y, Qian L, Xu B, Xi W (2018) Addition flame-retardant effect of nonreactive phosphonate and expandable graphite in rigid polyurethane foams. J Appl Polym Sci 135(10): 45960.

81. Zarzyka I (2018) J Appl Polym Sci 135: 45478.

82. Zhang K, Hong Y, Wang N, Wang, Y (2018) Flame retardant polyurethane foam prepared from compatible blends of soybean oil-based polyol and phosphorus containing polyol. J Appl Polym Sci 135(5): 45779.

83. Bhoyate S, Ionescu M ,Kahol PK, Gupta RK (2019) Castor-oil derived nonhalogenated reactive flame-retardant-based polyurethane foams with significant reduced heat release rate. J Appl Polym Sci 136(13): 47276.

84. Cheng JJ, Qu WJ, Sun SH (2018) J Appl Polym Sci 135: 46436.

85. Liu DY, Zhao B, Wang GS, Liu PU, Liu YQ (2018) J Appl Polym Sci 135: 46434.

86. Jia D, Hu J, He J, Yang R (2019) J Appl Polym Sci 136: 47493.

87. De Avila D, Magalhaes WLE, Petzhold CL (2018) Polym Compos 9: E1770-E1777.

88. Li Z, Shen Y, Gu X, Li J, Gao Y (2019) A novel underwater acoustically transparent material: Fluorosilicone polyester polyurethane. J Appl Polym Sci 136(34): 47894. 
89. Baghban S, Khorasani M, Sadeghi GMM (2018) Soundproofing flexible polyurethane foams: The impact of polyester chemical structure on the microphase separation and acoustic damping. J Appl Polym Sci 135(46): 46744.

90. Jayakumari VG, Shamsudeen RK, Rajeswari R, Mukundan T (2019) Viscoelastic and acoustic characterization of polyurethane-based acoustic absorber panels for underwater applications. J Appl Polym Sci 136(10): 47165.

91. Ji Y, Chen S (2019) Optimization of acoustic performances of a new tung oleic acid-based composite polyurethane foam J Appl Polym Sci 136(33): 47861.

92. Yang L, Wang Y, Peng X (2017) J Macromol Sci Part A Pure Appl Chem 54(8): 516-523.

This work is licensed under Creative Commons Attribution 4.0 License

DOI: $10.19080 /$ AJOP.2020.03.555618
93. Qiao, Z, Xu D, Yao Y, Song S, Yin M, Luo (2019) Synthesis and antifouling activities of fluorinated polyurethanes. J Polym Int 68(7): 1361-1366.

94. Tsen WC, Lee CF, Su YR, Gu JH, Suen MC (2019) Effect of novel aliphatic fluoro-diol content on synthesis and properties of waterborne polyurethanes. J Appl Polym Sci 136(21): 47356.

95. Sun Z, Fan H, Chen Y, Huang J (2018) J Polym Int 67: 78-84.

96. Kranauskaite M, Macutkevic J, Banis J, Kuznetsov V, Letellier M, et al. (2018) Polym Compos 39: E1834-E1840.

97. Hwang C, Sultane PS, Kang DH, Breluwski CW (2018) Polym Int 67: 1664-1669.

98. Tan CJ, Lee JLL, Ang BC, Andriyana A, Chagnon G (2019) Design of polyurethane fibers: Relation between the spinning technique and the resulting fiber topology. J Appl Polym Sci 136(26): 47096.

\section{Your next submission with Juniper Publishers will reach you the below assets}

- Quality Editorial service

- Swift Peer Review

- Reprints availability

- E-prints Service

- Manuscript Podcast for convenient understanding

- Global attainment for your research

- Manuscript accessibility in different formats ( Pdf, E-pub, Full Text, Audio)

- Unceasing customer service

Track the below URL for one-step submission https://juniperpublishers.com/online-submission.php 